\title{
Uma história institucional da tuberculose no Chile: o Programa de Controle da Tuberculose, 1973-2013
}

\author{
An institutional history of tuberculosis in Chile: \\ the Tuberculosis Control Program, 1973-2013
}

\author{
Juliana Manzoni Cavalcanti \\ Pós-doutoranda, Programa de Pós-graduação em História das Ciências e da Saúde/Casa de Oswaldo Cruz/Fiocruz. \\ jujumanzoni@yahoo.com.br
}

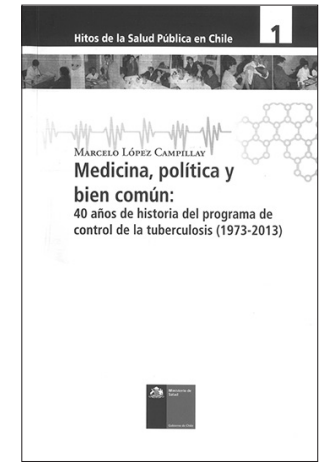

LÓPEZ CAMPILLAY,

Marcelo. Medicina, política y bien comum: 40 años de historia del programa de control de la tuberculosis, 1973-2013. Santiago: Ministerio de la Salud. 2015. 176p.
$\mathrm{O}^{\prime}$ livro Medicina, política y bien comum: 40 años de historia del programa de control de la tuberculosis, 1973-2013, de autoria do historiador e professor do Programa de Estudos Médicos Humanísticos (PEMH) da Pontifícia Universidade Católica do Chile Marcelo López Campillay, oferece aos historiadores da saúde e da medicina, bem como aos interessados no assunto, um bom panorama das ações médicas e estatais chilenas relativas à tuberculose empreendidas durante o século XX. É o primeiro livro da série "Hitos de la salud pública em Chile" (Marcos da saúde pública no Chile), que procura preservar a história da saúde pública no país e refletir sobre ela, tendo por objetivo destacar as políticas públicas adotadas. Resultado de um projeto interdisciplinar que reuniu membros da Unidade de Patrimônio Cultural da Saúde do Ministério da Saúde, do Programa de Controle e Eliminação da Tuberculose e do PEMH da Pontifícia Universidade Católica do Chile, o livro revela que é possível combinar o relato dos partícipes dessas políticas a uma análise histórica e crítica dos eventos passados, sem a mitificação de personagens e instituições. Ainda que o Programa de Controle da Tuberculose (PCT), objeto de análise do livro, seja encarado atualmente como uma política de saúde pública exitosa, o autor enfatiza seu processo de construção, operante também durante seu período de funcionamento, que reflete uma série de negociações, adaptações e equívocos. Nesse sentido, delineia a história da luta contra a tuberculose recorrendo frequentemente aos contextos nacional e internacional.

Ainda que no título o período temporal esteja compreendido entre 1973 e 2013, tempo de funcionamento do programa, o autor inicia sua narrativa no século XIX, pois afirma ser primordial entendermos as mudanças ocorridas antes da criação do programa. Ele divide tais mudanças em duas fases históricas, a primeira que chamou de "tuberculinização" da sociedade, isto é, o momento em que a tuberculose era encarada como a síntese dos 
problemas sociais surgidos com a modernização da sociedade chilena, e a segunda de "a era dos antibióticos", marcada pela proeminência do tratamento com a nova terapêutica. Os dois primeiros capítulos tratam dessa primeira fase e descortinam a atuação da tuberculose e as respostas a ela no contexto social, político e econômico chileno do século XIX até os anos 1930. O autor começa sua história social da tuberculose no Chile pelo reconhecimento da relação causal entre a tuberculose e o "câmbio de civilização" ocorrido no século XIX, com o aumento populacional e a urbanização que causaram, por sua vez, a aglomeração de pessoas e as deficiências na alimentação. Em seguida, revela-nos que a chamada luta antituberculosa inaugurada com a nutrição materno-infantil e com a criação de sanatórios, por iniciativa da sociedade civil, transforma-se, nos anos 1930, em política estatal de saúde com a ajuda da consolidação da seguridade social e da tisiologia como disciplina médica.

No terceiro capítulo, inicia-se a análise da "era dos antibióticos", período entre 1952 e 1973, calcada, principalmente, nas entrevistas de médicos da Faculdade de Medicina da Universidade do Chile envolvidos com as bases do PCT, mas balizadas por considerações acerca da configuração política e econômica internacional. Esses anos são vistos, portanto, como o prelúdio para a etapa de funcionamento do PCT. Ressalta a sobrevalorização dos antibióticos nos anos 1950 que acabou atrapalhando o controle da tuberculose devido à ideia de que a doença não era mais um grave problema de saúde pública chilena. Não é necessariamente uma singularidade histórica do Chile, conforme afirma o autor, pois a tuberculose continua a ser prevalente em regiões do globo onde a assistência à saúde é precária, o que mostra que as inovações terapêuticas não são eficazes quando se alija o acompanhamento médico e social contínuo, método anterior à era dos antibióticos.

Nos capítulos 4 e 5, temos o exame da história do PCT, dividida em dois períodos. O momento entre 1973 e 1994, quando inicialmente o programa foi ameaçado pela nova prioridade do governo civil-militar em relação aos gastos com a saúde até meados dos anos 1980, e um momento de maior estabilidade com relação à disponibilidade de recursos, mas no qual ainda estavam ausentes os meios para diminuir a morbidade da doença. O segundo período, abordado no capítulo 5, vai de 1994 a 2013, e é marcado pelo processo de globalização, com a crescente preocupação em face da vulnerabilidade social dos imigrantes e da ascensão de portadores de HIV com tuberculose, e pelo neoliberalismo, que veio a priorizar aspectos econômicos em detrimento dos sanitários. À época se buscou manter a tuberculose na agenda de prioridades da saúde pública nacional, ainda que a mortalidade tenha sido reduzida drasticamente e influenciado a diminuição de recursos do programa. Apesar disso, o principal laboratório de tuberculose do país tornava-se referência supranacional pela Organização Panamericana de Saúde e criava-se o Programa de Controle e Eliminação da Tuberculose (Procet) em 2000, o qual, segundo o autor, demonstra que o Chile estava em um patamar de controle da tuberculose que poucos países apresentavam.

Temos, assim, cerca da metade do livro dedicado ao período anterior ao PCT, o que mostra uma preocupação em revelar minimamente o percurso histórico anterior à implementação do programa, buscando explicar suas possíveis raízes ao compreendê-lo como um arranjo da relação entre a sociedade chilena, a tuberculose e as ações estatais voltadas para a doença. Apesar de a obra não ser direcionada ao círculo acadêmico, delimitou-se o objeto de estudo com trabalhos de referência da área como, por exemplo, os que tratam da ascensão da 
atenção primária nos sistemas de saúde latino-americanos e da complexidade teórico e prática dos cenários médicos da América Latina, que conjugam doenças vistas como de países desenvolvidos com enfermidades seculares.

O livro é, portanto, uma iniciativa bem-sucedida de aproximar historiadores e profissionais de saúde, e deveria ser mais disseminada, tendo em vista o novo cenário epidêmico e endêmico da América Latina, no qual novas e antigas doenças continuam presentes. A atual epidemia da zika, disseminada por um vetor (Aedes aegypti) que conhecemos há mais de um século, é uma excelente oportunidade para concretizar essa aproximação, mas neste caso de forma ativa e imediata. A história é muitas vezes encarada como um meio de determinar o que deu certo e o que saiu errado, mas ela também é capaz de sensibilizar o público, os profissionais e as autoridades estatais em relação à natureza social das doenças. No caso da tuberculose, por exemplo, não bastou que uma promissora tecnologia médica - os antibióticos - estivesse disponível para que a doença fosse eliminada. A adesão dos pacientes ao tratamento e o comprometimento do Estado em financiar, durante longos períodos, as políticas de erradicação e controle foram também primordiais para se alcançar uma baixa prevalência da tuberculose no Chile. O historiador das ciências da saúde deve, portanto, participar não apenas como um expositor do que ocorreu em relação às políticas de saúde já implementadas, mas aliar seus conhecimentos aos da epidemiologia e da biologia para auxiliar a formular as políticas de saúde contemporâneas.

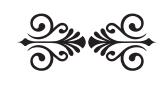

